\title{
Diagnostic significance of diaphragmatic height index in traumatic diaphragmatic rupture
}

\author{
Junsik Kwon, John Cook-Jong Lee, Jonghwan Moon \\ Department of Trauma Surgery, Ajou University School of Medicine, Suwon, Korea
}

\begin{abstract}
Purpose: Traumatic diaphragmatic rupture resulting from blunt trauma is usually severe. However, it is often overlooked during initial evaluation because there are no characteristic signs and symptoms. Thus, this study aimed to determine the clinical characteristics of diaphragmatic rupture caused by blunt trauma and investigate the diagnostic usefulness of diaphragmatic height index (DHI) measured using chest radiographs.

Methods: The cohort comprised patients who were admitted due to diaphragmatic rupture from blunt trauma. Patients were divided into 2 groups; the control group comprised patients with blunt trauma who were matched for age, sex, and Injury Severity Score, while the DHI group comprised patients with diaphragmatic rupture from blunt trauma. Receiver operating characteristic curve was used to determine the cutoff value of DHI for diaphragmatic injury. The sensitivity, specificity, predictability, accuracy, and likelihood ratio of the cutoff were then determined.

Results: A total of 60 patients were confirmed to have diaphragmatic rupture. The mean $\mathrm{DHI}$ in patients with diaphragmatic rupture on the right and left side were both significantly different compared to that in the control group. A DHI cutoff value of $>1.31$ showed $71 \%$ sensitivity and $87 \%$ specificity for diagnosing right diaphragmatic rupture, while a cutoff value of $<0.43$ showed $87 \%$ sensitivity and $76 \%$ specificity for diagnosing left diaphragmatic rupture.

Conclusion: DHI can be useful in the diagnosis of diaphragmatic rupture. DHI as determined using chest radiographs in patients with blunt abdominal trauma, particularly in those ineligible for diagnostic work-up, may help in the diagnosis of diaphragmatic rupture.
\end{abstract}

[Ann Surg Treat Res 2019;97(1):36-40]

Key Words: Diaphragm, Abdominal injuries, Multiple trauma

\section{INTRODUCTION}

Traumatic diaphragmatic rupture due to blunt trauma tends to be severe, as it is often accompanied by various other thoracoabdominal injuries. Given that there are no characteristic signs or symptoms for its early detection, traumatic diaphragmatic rupture may be easily overlooked during initial evaluation. Delayed treatment may lead to fatal outcomes such as respiratory failure, hernia, or incarceration; therefore, the possibility of diaphragmatic rupture should be considered in the early stage of evaluation and treatment of patients with multiple trauma [1,2]. However, diaphragmatic rupture is known to be difficult to diagnose prior to surgery [3]. Although computed tomography has shown excellent sensitivity for diagnosing various organ injuries in the chest and abdomen, it has lesser sensitivity to diaphragmatic rupture [4]. Therefore, this study aimed to investigate the diagnostic usefulness of using the diaphragmatic height index (DHI) [5], which can be easily measured using chest radiographs alone, for diaphragmatic rupture.
Received November 22, 2018, Revised February 10, 2019,

Accepted April 9, 2019

Corresponding Author: Jonghwan Moon

Department of Trauma Surgery, Ajou University School of Medicine, 164

Worldcup-ro, Yeongtong-gu, Suwon 16499, Korea

Tel: +82-31-219-7495, Fax: +82-31-219-7781

E-mail: soyo1226@naver.com

ORCID code: https://orcid.org/0000-0002-4630-3301
Copyright (C) 2019, the Korean Surgical Society

(c) Annals of Surgical Treatment and Research is an Open Access Journal. All articles are distributed under the terms of the Creative Commons Attribution NonCommercial License (http://creativecommons.org/licenses/by-nc/4.0/) which permits unrestricted non-commercial use, distribution, and reproduction in any medium, provided the original work is properly cited. 


\section{METHODS}

\section{Patient selection}

This study included patients with blunt trauma who were admitted to a single trauma center between March 2010 and December 2016. Patients diagnosed with diaphragmatic rupture were included. Of those, patients with a penetrating injury or age less than 16 years and those without chest radiographs or electronic medical records were excluded. The patients were divided into 2 groups; patients in the control group (group C) were selected through propensity score matching of age, sex, and Injury Severity Score among trauma patients who were admitted during the same period, while the DHI group comprised patients with diaphragmatic rupture from blunt trauma. Patients in the DHI group were further classified into groups $\mathrm{R}$ and $\mathrm{L}$ for those with injuries on the right and left side of the diaphragm, respectively. All demographic data, including age, sex, height, weight, and body mass index, and traumarelated data were retrospectively obtained from electronic medical records.

\section{Measurement of DHI}

DHI was measured using the standard anteroposterior chest radiographs of the patients. All images were digitized and registered in the Picture Archiving Communication System, and 2 trauma surgeons with 5 years of experience measured the DHI. To reduce bias, the surgeons were blinded to the patient information. DHI was calculated using the method described by Pornrattanamaneewong et al. [5] (Fig. 1). The calculation consists of 5 steps as follows: (1) drawing the reference line (R line) following the bottom of the 10th thoracic vertebrae, (2) marking the diaphragm's dome and drawing lines A and B parallel to line $\mathrm{R}$, (3) determining the distance between lines A and $B$, (4) measuring the length of the 10th thoracic vertebrae, and (5) dividing the difference between lines A and B found in step 3 by the length of the 10th thoracic vertebrae in step 4 . The quotient is the DHI. However, because the DHI group comprised patients with diaphragmatic rupture, the location of the dome in step 2 may actually not be the diaphragm, but the shadow of the organ that has escaped into the ribcage. Given that the height of the right diaphragm is generally higher than that of the left, we considered that the value of DHI is positive when the right side is higher, and it is negative when the left side is higher.

\section{Statistical analysis}

All statistical analyses were performed using IBM SPSS Statistics ver. 23.0 (IBM Co., Armonk, NY, USA). Student t-test and analysis of variance were used for quantitative data and chi-square test was used for qualitative data. A P-value $<0.05$ was considered significant. To determine the cutoff value for diaphragmatic injury, receiver operating characteristic curve was drawn by dividing the patients with right and left side injuries. The sensitivity, specificity, predictability, accuracy, and likelihood ratio were determined.

\section{Ethics statement}

This retrospective study was approved by the Institutional Review Board of Ajou University (approval number: AJIRB-MEDMDB-17). Informed consent was waived by the board due to the observational nature of the study.

\section{RESULTS}

\section{Study population}

Of the 14,340 patients admitted to our trauma center during the study period, 13,359 had blunt trauma. Among them, 60 patients $(0.45 \%)$ had diaphragmatic rupture. All 60 cases of diaphragmatic rupture were determined through surgery, among which 31 were in the right (group $\mathrm{R}$ ), and 29 were in the
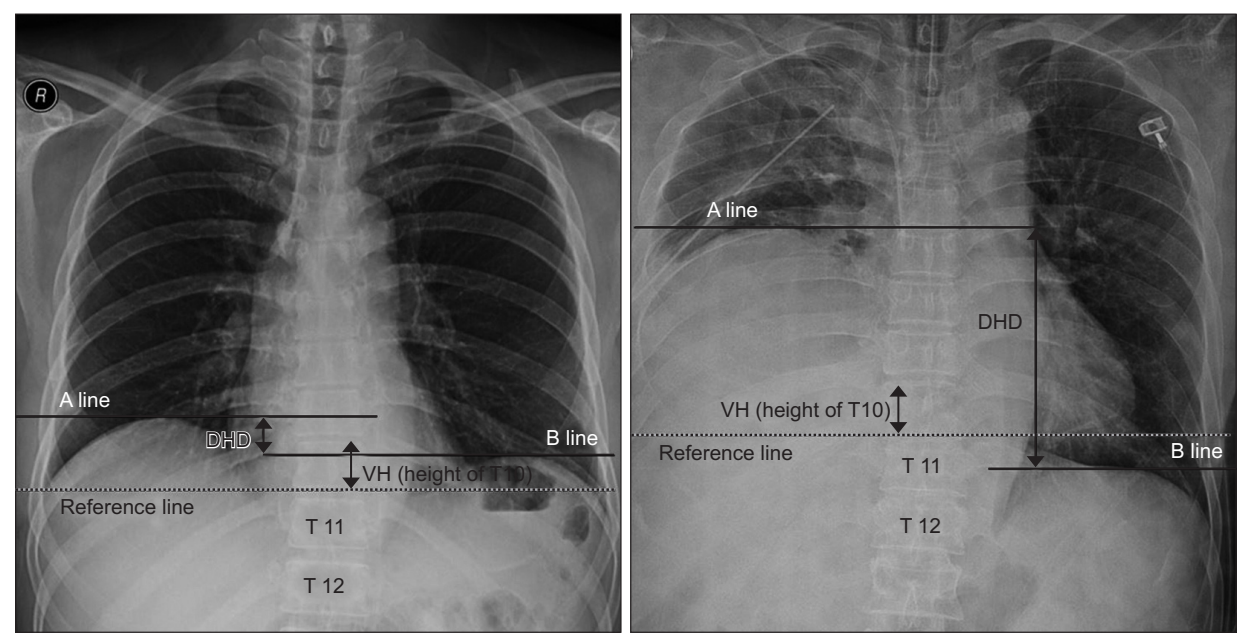

Fig. 1. Anteroposterior chest radiographs used for calculating the diaphragmatic height index. DHD, diaphragmatic height difference; VH, vertebrae height. 


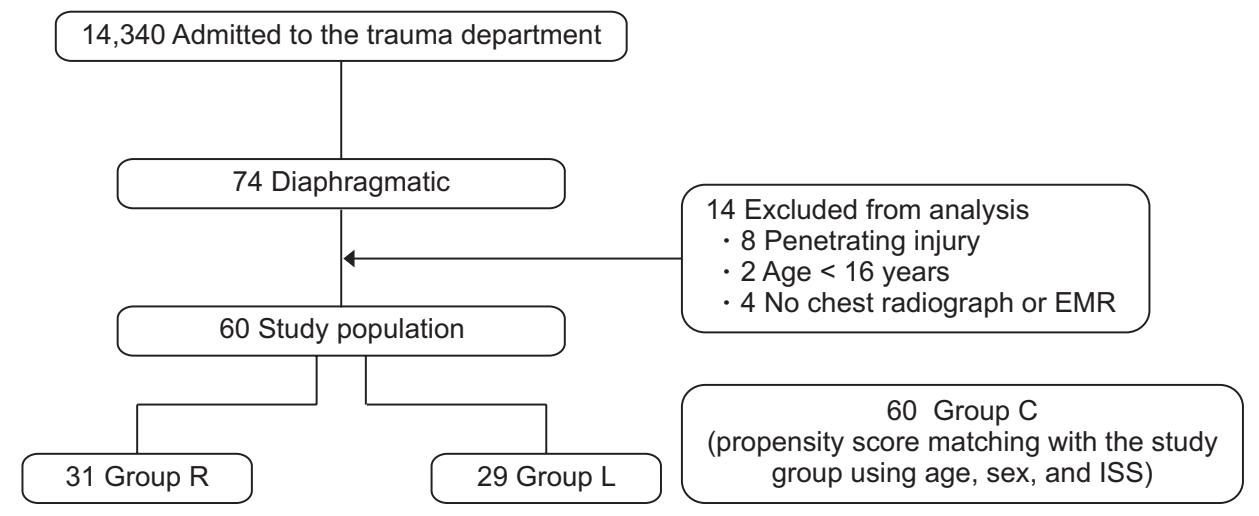

Fig. 2. Flow chart of patient selection in the study. EMR, electronic medical record; ISS, injury severity score; Group $\mathrm{R}$, right side of the diaphragm; Group L, left side of the diaphragm; Group C, control group.

Table 1. Demographic data

\begin{tabular}{|c|c|c|c|c|}
\hline Variable & Group R ( $n=31)$ & Group L (n = 29) & Group C $(n=60)$ & P-value \\
\hline Sex, female:male & $8: 23$ & $5: 24$ & $16: 44$ & NS \\
\hline Age (yr) & $49.0 \pm 12.5$ & $49.52 \pm 12.81$ & $50.6 \pm 18.3$ & NS \\
\hline Height $(\mathrm{cm})$ & $169.9 \pm 7.6$ & $167.28 \pm 8.25$ & $168.1 \pm 10.0$ & NS \\
\hline Weight (kg) & $65.9 \pm 10.9$ & $63.87 \pm 14.35$ & $63.5 \pm 10.7$ & NS \\
\hline Body mass index $\left(\mathrm{kg} / \mathrm{m}^{2}\right)$ & $22.8 \pm 3.3$ & $22.84 \pm 4.98$ & $22.4 \pm 2.9$ & NS \\
\hline ISS & $29.6 \pm 13.9$ & $25.31 \pm 14.54$ & $29.3 \pm 127.7$ & NS \\
\hline Cause of injury & & & & $<0.001^{\mathrm{a}, \mathrm{b})}$ \\
\hline TA & 15 & 12 & 26 & \\
\hline Fall & 10 & 8 & 15 & \\
\hline Others & 6 & 9 & 29 & \\
\hline $\mathrm{DHI}$ & $2.2 \pm 1.6$ & $-1.21 \pm 2.1$ & $0.83 \pm 0.5$ & $<0.001^{\mathrm{a}, \mathrm{b})}$ \\
\hline
\end{tabular}

Values are expressed as the mean \pm standard deviation or number.

Group R, right side of the diaphragm; Group L, left side of the diaphragm; Group C, control group; NS, not significant; TA, traffic accident; DHI, diaphragmatic height index.

${ }^{\text {a) }}$ Statistical significance between groups $\mathrm{R}$ and $\mathrm{C}$. ${ }^{\text {b) }}$ Statistical significance between groups $\mathrm{L}$ and $\mathrm{C}$.

Table 2. Measurement values

\begin{tabular}{lcccc}
\hline & Group R & Group L & Group C & P-value \\
\hline No. of patients & 31 & 29 & 60 & \\
DHI & $2.2 \pm 1.6$ & $-1.21 \pm 2.1$ & $0.83 \pm 0.5$ & $<0.001$ \\
\hline
\end{tabular}

Values are expressed as the means \pm standard deviations.

Group R, right side of the diaphragm; Group L, left side of the diaphragm; Group C, control group.

left (group L) (Fig. 2). Some of these cases included incidental findings of diaphragmatic rupture during surgery in the absence of any suspicion of diaphragmatic rupture. Group R comprised 23 male patients, and the average age was 49 years. Meanwhile, group L comprised 24 male patients, and the average age was also 49 years. The patients' characteristics are shown in Table 1. Except for the mechanism of injury, there was no significant difference in the patients' demographic characteristics between the DHI and control groups.

\section{Diaphragmatic height index}

The average DHI of group R was $2.2 \pm 1.6$, which was
Table 3. Diagnostic test for the DHI cutoff values

\begin{tabular}{lcc}
\hline \multicolumn{1}{c}{ Variable } & $\begin{array}{c}\text { DHI }>1.31 \\
\text { for RDH }\end{array}$ & $\begin{array}{c}\mathrm{DHI}<0.43 \\
\text { for LDH }\end{array}$ \\
\hline Sensitivity & $71 \%$ & $76 \%$ \\
Specificity & $87 \%$ & $87 \%$ \\
Positive predictive value & $73 \%$ & $73 \%$ \\
Negative predictive value & $85 \%$ & $88 \%$ \\
Positive likelihood ratio & 5.32 & 5.69 \\
Negative likelihood ratio & 0.33 & 0.28 \\
Accuracy & $81 \%$ & $83 \%$ \\
\hline
\end{tabular}

$\mathrm{DHI}$, diaphragmatic height index; $\mathrm{RDH}$, right diaphragmatic hernia; LDH, left diaphragmatic hernia.

significantly higher than that of group $C$ at $0.83 \pm 0.5$. By contrast, the DHI value of group L was $-1.2 \pm 2.1$, which was significantly lower than that of group C (Table 2). Under the receiver operating characteristic curve, a DHI cutoff value of $>1.31$ for right diaphragmatic injury yielded a $71 \%$ sensitivity and $87 \%$ specificity. Meanwhile, a cutoff value of $<0.43$ for left diaphragmatic injury yielded a $76 \%$ sensitivity and $87 \%$ specificity (Table 3). Intrarater agreement and interrater 
agreement were 0.76 and 0.85 , respectively.

\section{DISCUSSION}

In general, diaphragmatic injury is rarely diagnosed in patients with injury who are admitted to a hospital; usually, less than $10 \%$ of diaphragmatic injuries are reported [6-10]. Except for penetrating wounds as a cause, right-sided diaphragmatic injury due to blunt trauma is even rarer. One study reported that the rate of left-sided diaphragmatic injury is 25 times higher than that of the right side [11]. This seems to be because the right diaphragm is protected by the liver, which is firmly fixed in place by several ligaments, while the left diaphragm is located above the stomach or spleen, which are more mobile than the liver. The rate of left and right diaphragmatic injury varies in several studies [12,13]. In contrast, the frequencies of right and left diaphragm injury observed in this study were similar. This is likely because the patients were limited to those with diaphragmatic injury and diaphragmatic hernia confirmed through surgery rather than all diaphragmatic injury. A previous study on traumatic diaphragmatic injury diagnosed via autopsy also reported no difference in the frequency of left and right diaphragmatic rupture [14]. The relatively lower incidence of right-sided diaphragmatic rupture is because right-sided diaphragmatic rupture and diaphragmatic hernia are harder to diagnose than left-sided diaphragmatic injury, except when diagnosis is made via autopsy. Left-sided diaphragmatic rupture is relatively easier to determine through gastric gas patterns in the chest that can be assessed via standard chest radiography, $\mathrm{CT}$, or nasogastric tube. Meanwhile, right diaphragmatic rupture is difficult to diagnose as it does not show such abnormal chest radiographic findings or distinctive clinical symptoms $[8,15,16]$. CT is an important diagnostic modality in patients with thoracoabdominal injury due to blunt trauma. However, its sensitivity is relatively lower for diaphragmatic injury than that for other organ injuries [4]. Diaphragmatic injury is often accompanied by multiple organ injuries, as it is caused by a strong impact to the abdomen. Thus, performing CT before emergency surgery is sometimes impossible due to hemodynamic instability. Even if laparotomy is performed, diaphragmatic injury is sometimes not recognized until after the surgery because of the fast-paced control for hemostasis or intraperitoneal organ injuries [17]. Delayed diagnosis of diaphragmatic injury can result in sequelae that can be fatal to the patient's prognosis, such as strangulated incarceration of the gastric hernia and continuous bleeding in the peritoneal cavity, which can result in hemostasis failure [18]. Surgery is the only treatment modality for diaphragmatic injury. Hence, acquiring information in the initial evaluation or recognizing the possibility of diaphragmatic injury prior to performing emergency surgery is important for improving patient prognosis and can be helpful in preventing unnecessary repeated laparotomy.

Standard chest radiography is generally performed in the initial evaluation of trauma patients because it is fast and simple and does not require the patient to move. A simple chest radiography is mostly possible prior to surgery or upon admission even in patients who cannot undergo sufficient examinations of the entire body due to hemodynamic instability. Therefore, there have been attempts in diagnosing diaphragmatic rupture by combining simple chest radiographs and several clinical findings. One study reported that an elevated diaphragm is a strong indicator of diaphragmatic rupture [10], but it was not able to provide a standard to compare the findings of a normal diaphragm and diaphragmatic rupture other than the difference in diaphragmatic height of both sides. Furthermore, an elevated diaphragm alone based on standard chest radiography (i.e., it is not correlated with clinical findings) has low sensitivity for diagnosing diaphragmatic rupture [3]. The difference in the height of the diaphragm, that is, the right side being higher than the left side by 1.5 to $2.0 \mathrm{~cm}$, has to be considered in the application of elevated diaphragm in the diagnosis of diaphragmatic rupture [19]. Moreover, the height of the diaphragm being influenced by the patient's physical condition should also be considered when using an elevated diaphragm as a marker for diaphragmatic injury. Suwatanapongched et al. [20] set the thoracic vertebrae as reference to describe the location of the right and left domes of the diaphragm. To consider the patient's physical variables, Pornrattanamaneewong et al. [5] used the height of the 10th thoracic vertebrae for calculating DHI to diagnose diaphragmatic paralysis. Because $\mathrm{DHI}$ is a proportional value using a simple anatomical reference, it is easy to compute and recreate. In this study, DHI was used to determine the side of diaphragmatic rupture. The mean DHI in the control group was not significantly different from that in a study by Pornrattanamaneewong et al. [5] ( $0.83 \pm 0.5$ vs. $0.6 \pm 0.4)$, in which the control group comprised patients without chest or abdominal injuries who underwent orthopedic surgery in the extremities. Because the right diaphragm is generally higher than the left, the elevation of the right diaphragm results in a positive DHI, and elevation of the left diaphragm yields a negative DHI.

In this study, the DHI in the patients with right and left diaphragmatic rupture was significantly different than that in the control group, indicating that DHI can have a diagnostic significance in diaphragmatic rupture. The DHI cutoff values showed high sensitivity and specificity for both right and left sides. Moreover, they showed moderate reliability. However, as this study was a single-center retrospective study conducted in an Asian population, the results should be verified in other racial groups. Moreover, because all the patients in the control 
group did not undergo open surgery, the possibility that a small number of diaphragmatic ruptures were included was not completely ruled out. Furthermore, because an elevated diaphragm can be found in several conditions including diaphragmatic paralysis, atelectasis, thoracoabdominal tumor, subdiaphragmatic abscess, and dilation of the large bowel [21], the mechanism of injury and clinical findings must be considered when using DHI for the diagnosis of diaphragmatic rupture.

In conclusion, our findings showed that DHI computed using standard chest radiographs can be helpful in diagnosing diaphragmatic rupture. DHI as computed using chest radiographs in patients with blunt abdominal blunt trauma, particularly who are ineligible for additional diagnostic work-up such as CT, may help in the diagnosis of diaphragmatic rupture.

\section{CONFLICTS OF INTEREST}

No potential conflict of interest relevant to this article was reported.

\section{REFERENCES}

1. Hahn DM, Watson DC. Tension hydropneumothorax as delayed presentation of traumatic rupture of the diaphragm. Eur J Cardiothorac Surg 1990;4:626-7.

2. Montresor E, Procacci C, Guarise A, Minniti S, Bortolasi L, Nifosi F, et al. Strangulated traumatic hernia of the diaphragm. A report of two cases. Chir Ital 1999:51:471-6.

3. Miller L, Bennett EV Jr, Root HD, Trinkle JK, Grover FL. Management of penetrating and blunt diaphragmatic injury. J Trauma 1984:24:403-9.

4. Toombs BD, Sandler CM, Lester RG. Computed tomography of chest trauma. Radiology 1981;140:733-8.

5. Pornrattanamaneewong C, Limthongthang R, Vathana T, Kaewpornsawan K, Songcharoen P, Wongtrakul S. Diaphragmatic height index: new diagnostic test for phrenic nerve dysfunction. J Neurosurg 2012;117:890-6.

6. Desir A, Ghaye B. CT of blunt diaphragmatic rupture. Radiographics 2012;32:47798.

7. Bocchini G, Guida F, Sica G, Codella U, Scaglione M. Diaphragmatic injuries after blunt trauma: are they still a challenge?
Reviewing CT findings and integrated imaging. Emerg Radiol 2012;19:225-35.

8. Iochum S, Ludig T, Walter F, Sebbag H, Grosdidier G, Blum AG. Imaging of diaphragmatic injury: a diagnostic challenge? Radiographics 2002;22 Spec No:S103-16.

9. Mirvis SE, Shanmuganagthan K. Imaging hemidiaphragmatic injury. Eur Radiol 2007;17:1411-21.

10. Nchimi A, Szapiro D, Ghaye B, Willems V, Khamis J, Haquet L, et al. Helical CT of blunt diaphragmatic rupture. AJR Am J Roentgenol 2005;184:24-30.

11. Hood RM. Traumatic diaphragmatic hernia. Ann Thorac Surg 1971;12:311-24.

12. Sukul DM, Kats E, Johannes EJ. Sixtythree cases of traumatic injury of the diaphragm. Injury 1991;22:303-6.

13. Shah R, Sabanathan S, Mearns AJ, Choudhury AK. Traumatic rupture of diaphragm. Ann Thorac Surg 1995;60:1444-9.

14. Puffer P, Gaebler M. Traumatic diaphragmatic rupture in a forensic medicine autopsy sample. Beitr Gerichtl Med 1991; 49:149-52.

15. Sharma AK, Kothari SK, Gupta C, Menon P, Sharma A. Rupture of the right hemidiaphragm due to blunt trauma in children: a diagnostic dilemma. Pediatr Surg Int 2002;18:173-4.

16. Gelman R, Mirvis SE, Gens D. Diaphragmatic rupture due to blunt trauma: sensitivity of plain chest radiographs. AJR Am J Roentgenol 1991;156:51-7.

17. Hamidian Jahromi A, Pennywell D, Owings JT. Does a negative emergency celiotomy exclude the possibility of significant diaphragmatic injury? A case report and review of the literature. Trauma Mon 2016;21:e25053.

18. Beal SL, McKennan M. Blunt diaphragm rupture. A morbid injury. Arch Surg 1988; 123:828-32.

19. Collins J, Stern EJ. Chest radiology: The Essentials. 9th ed. Philadelphia: Lippincott Williams \& Wilkins; 2008. Normal anatomy of the chest; 1-15.

20. Suwatanapongched T, Gierada DS, Slone RM, Pilgram TK, Tuteur PG. Variation in diaphragm position and shape in adults with normal pulmonary function. Chest 2003;123:2019-27.

21. Krige JE, Beckingham IJ. ABC of diseases of liver, pancreas, and biliary system. BMJ 2001;322:537-40. 